\title{
Small Size Cylindrical Molten Carbonate Fuel Cells and Future Approaches for Decreasing Working Temperature
}

\author{
F. Rossi ${ }^{a}$, A. Nicolini ${ }^{a}$, P. Di Profio ${ }^{b}$ \\ ${ }^{a}$ Department of Industrial Engineering, University of Perugia, \\ via G.Duranti 67, 06125 Perugia, Italy \\ ${ }^{\mathrm{b}}$ Center of Excellence on Innovative Nanostructured Materials, University of Perugia, \\ Via Elce di Sotto 8, 06123 Perugia, Italy
}

The paper deals with the development of an original small size cylindrical molten carbonate fuel cell (SSMCFC) and an investigation for decreasing its working temperature. High benefits are obtained by the proposed configuration in terms of construction time and costs, thermal dispersion minimization, global efficiency; minimization of gases tight problems, compression strain uniformity on the contact surface. A $1 \mathrm{~kW}$ stack constituted by 15 single cells was tested with good results. However, SSMCFC is characterized by high working temperatures $\left(600-700^{\circ} \mathrm{C}\right)$. Thus, high temperatures and the typical used electrolyte may accelerate the cell components breakdown and corrosion. An investigation on using ionic liquids as electrolyte support instead of a lithium aluminate porous element was carried out by an experimental facility. Test results allowed to individuate the optimum kind of ionic liquid for SSMCFC matrix support and possible other adjustment for performances improving.

\section{Introduction}

An original cylindrical small size molten carbonate fuel cell (SSMCFC) was designed, optimized, tested and patented (1-4). The cell main peculiarity is the original architecture which involves both elements geometry and gases arrangements. High benefits are obtained by the proposed configuration. High mechanical stability is obtained by an innovative cell configuration. An innovative tie system was designed and installed. Cell elements (electrodes, electrolyte and distribution plates) are placed into a cylindrical vessel. Sealing is enhanced and compression strain is kept uniform along cell surface by the tie system and an original stacking frame. The original system is also characterized by low heat losses. Different configurations were built and tested in order to optimize SSMCFC performances. Final Tests were carried out on the SSMCFC optimized configuration by a $1 \mathrm{~kW}$ stack constituted by 15 single cells. Voltage/current characteristic was obtained at different working conditions. Maximum power density was also evaluated. Final tests were carried out by implementing a control and monitoring system for SSMCFC. New methodologies were proposed to optimize cell realization times and reduce industrialization costs: the target customer and the target price were established by an economical study. Results confirm the cell design as a promising solution for $\mu \mathrm{CHP}$ applications because of performances, durability and low costs. A further investigation was carried out in order to individuate solutions for decreasing SSMCFC working temperature. SSMCFCs are characterized by high working temperatures $\left(600-700^{\circ} \mathrm{C}\right)$. They have high efficiencies. The primary problem of 
SSMCFCs is durability: high temperatures and the typical used electrolyte may cause the components breakdown and corrosion; thus, the cell life may be not satisfactory for stationary use. The paper reports preliminary results on using ionic liquids (ILs) as electrolyte support for SSMCFC instead of a lithium aluminate porous element. ILs may help the charge separation at temperatures lower than $150-200^{\circ} \mathrm{C}$. They may support the carbonate ion production and passage through the matrix; thus, they may be suitable as matrix support or as electrolyte. The advantage is to reduce the SSMCFC working temperature; thus, a low temperature SSMCFC (LTMCFC) may be obtained. The LTMCFC life may be significantly longer than a traditional SSMCFC one. A single LTMCFC experimental facility was built and used for preliminary tests. Different kinds of ILs were tested in electrolytic solutions constituted by ILs (solvent) and lithiumpotassium carbonates (solute). Tests were led at temperatures lower than $200^{\circ} \mathrm{C}$ in order to verify the proposed solution at temperatures very low with respect to the traditional SSMCFC ones. The produced voltage and current were evaluated for each kind of IL matrix by varying the applied electrical load and temperature. Preliminary tests allowed to verify the suitability of the proposed solution and may be useful to individuate possible other adjustment for performances improving.

\section{SSMCFC development chronology}

A cylindrical small size molten carbonate fuel cell (SSMCFC) was patented (4). The proposed new geometry for MCFC was analyzed by thermofluidodynamic simulations which verified the suitability of the proposed design solutions (1). Materials, treatments and procedures suitable for SSMCFCs were investigated by manufacturing a single cell facility which was used as test bench (see Fig. 1) (2). The single cell facility was constituted by a single SSMCFC, exhaust and inlet manifolds, a frame for cell elements stacking and a heating system. The individuated materials and procedures were tested on a cylindrical SSMCFC test facility which is made by (see Fig. 2) (3):

1) a single cell which is constituted by a nickel-chrome anode, the electrolyte, a nickeloxide cathode and a gas distribution system. Gas distribution system is composed by the following steel plates, rings and nettings for each electrode:

- steel disk;

- steel ring in which a steel netting is placed. Gas internal flow is kept uniform by choosing a netting diameter smaller than the ring internal one;

- steel disk which separates the electrode chamber into two subchambers; holes are realized in the plate central zone where gases flow from the external subchamber to the internal one;

- steel netting which is mounted on a ring disk;

- holed steel disk which contacts the electrode.

The distribution system is characterized by high mechanical stability also for high working temperatures. Steel disks are low rigidity $1 \mathrm{~mm}$ thick. Sheets, rings and nettings may be easily formed by water or laser cutting methods with low realisation costs. The proposed distribution system allows obtaining the following benefits:

- Mechanical: divide each electrode chamber into two subchambers with uniform stack compression strain;

- Electrical: reduction of internal electrical resistance by enhancing the contact between two consecutive plates;

- Fluiddynamical: uniform gases distribution inside each chamber. 
The proposed distribution system can log catalysts for natural gas reforming which will be a future cell development.

2) Mechanical frame for cell stacking which is equipped with cup-springs to compress the stack.

3) Heating system for cell conditioning (dewaxing, start-up) and gas heating which is constituted by electrical resistors.

4) Exhaust and inlet manifolds (1).

5) Thermal insulation panels made by ceramic fibers which guarantee external surface temperature lower than $50^{\circ} \mathrm{C}$ when cell temperature is $645^{\circ} \mathrm{C}(2)$.

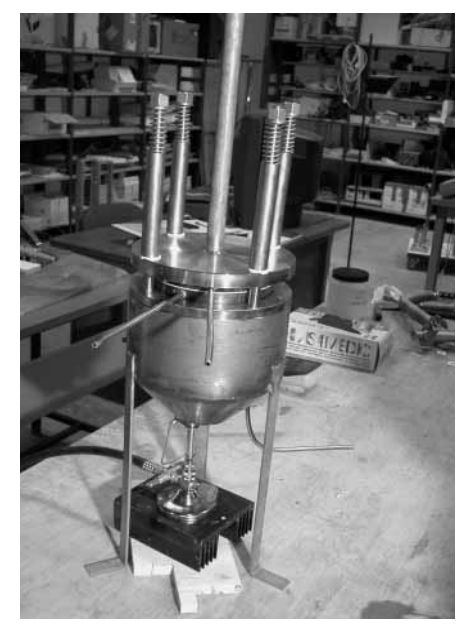

Figure 1. SSMCFC single cell facility (2)

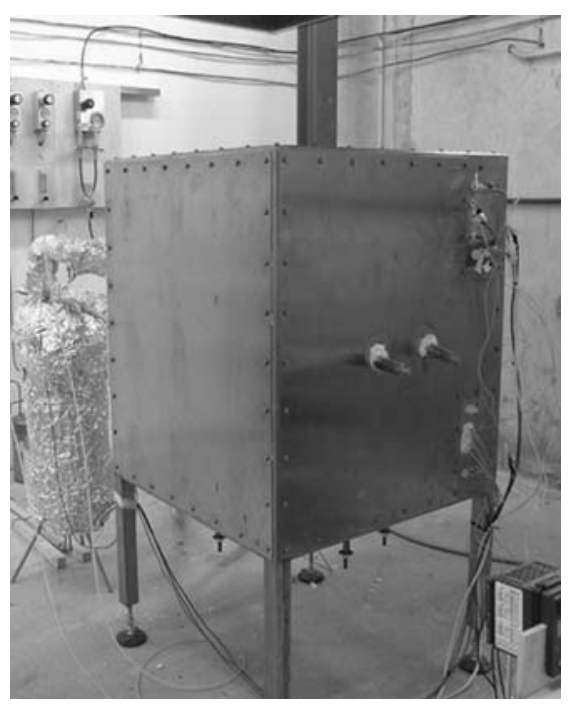

Figure 2. A SSMCFC configuration (3)

Cylindrical elements are obtained by a new injection printing patented technique which may be conveniently used for large scale productions because of time and cost benefits. Moreover, the proposed cylindrical configuration produces low heat losses because of high volume with respect to surface. Tests were carried out to determine voltage/current characteristic at different conditions: with and without steam into cathodic compartment at several times along cell lifetime. Cell resuming performances were also verified when 
both a temperature drop and a switching off event occur (3). A three cells SSMCFC was also tested by using the Figure 2 configuration; results confirmed the single cell ones. High current densities (approximately $170 \mathrm{~mA} / \mathrm{cm}^{2}$ ) were obtained; furthermore, performances stabilization was achieved by steam application at the cathodic compartment. A resume test was also carried out with positive results.

\section{The optimized SSMCFC configuration}

An optimized $1 \mathrm{~kW}$ SSMCFC configuration was proposed and tested. It is made by (see Figs. 3 and 4):

1) 15 single cells which are constituted by a nickel-chrome anode, the electrolyte, a nickel-oxide cathode and a gas distribution system. Gas distribution system is composed by low rigidity steel plates and nettings like Figure 2 configuration ones.

2) Mechanical frame for cell stacking which is equipped with cup-springs to compress the stack. The compression system was modified with respect to Figure 2 configuration one in order to improve the uniformity of the compression strain given by the headboards to the stack. Four external ties were added which acts in the plate central area. Thus, compression strain is uniformly distributed among the ties in the external stack area and eight ties in the plate external edge. This is obtained by a leaf spring system. In this way, compression strain distribution may be regulated in the conditioning phase, when organic bindings are eliminated.

3) Heating system for cell conditioning (dewaxing, start-up) and gas heating is constituted by ceramic band resistors applied on the stack external surface. Thus, a uniform heat distribution is achieved also for stacks constituted by a great number of single cells.

4) Exhaust and inlet manifolds (1).

5) Thermal insulation panels like Figure 2 configuration (2).

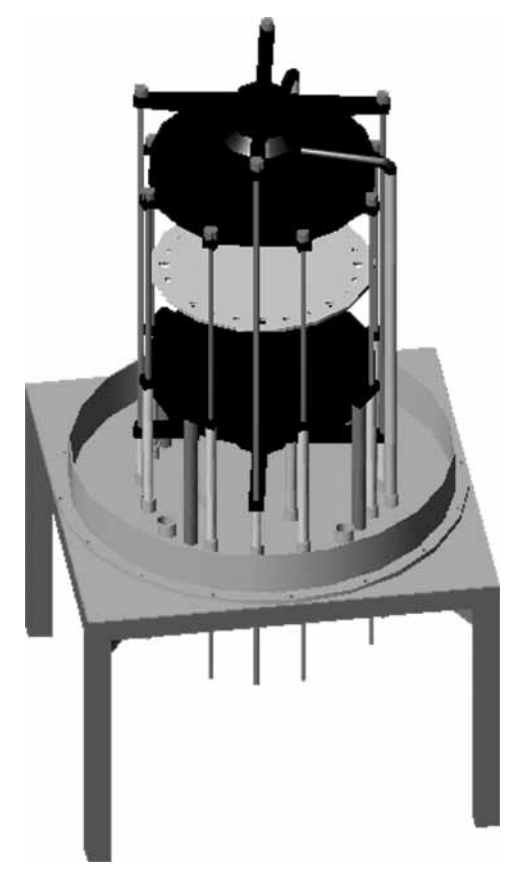

Figure 3. Optimized 1kW SSMCFC scheme. 
Figure 4 shows the proposed $1 \mathrm{~kW}$ SSMCFC equipped by a metallic vessel and the control and monitoring system. The new cell is scalable up to $5 \mathrm{~kW}$; the reported tests are relative to a hydrogen supply.

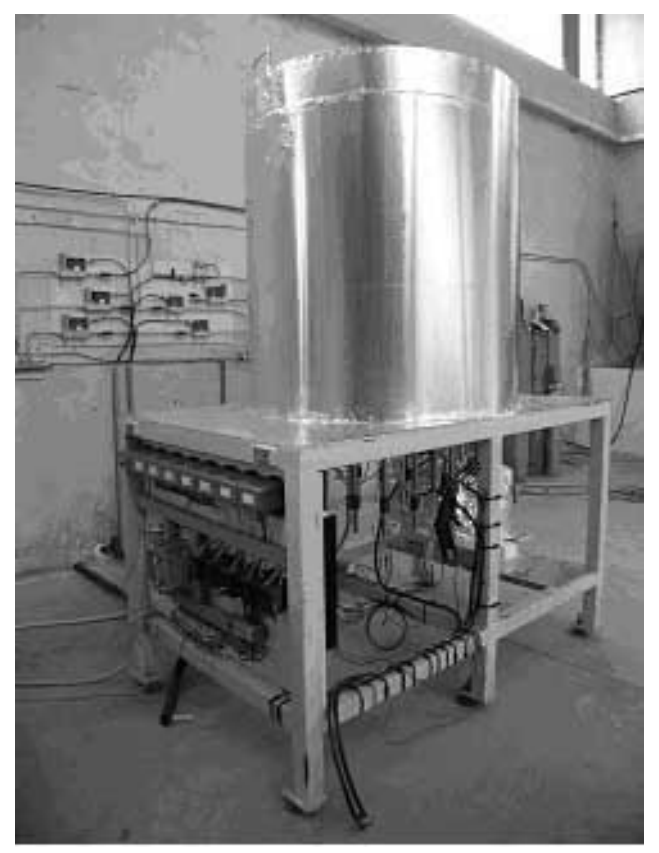

Figure 4. 1kW SSMCFC picture.

\section{Experimental Tests on the optimized 1kW SSMCFC}

Experimental tests were carried out to individuate the $1 \mathrm{~kW}$ SSMCFC Volt-Ampere characteristic (see Fig. 5). Tests were carried out by supplying steam at the cathodic compartment after dewaxing and start-up procedures.

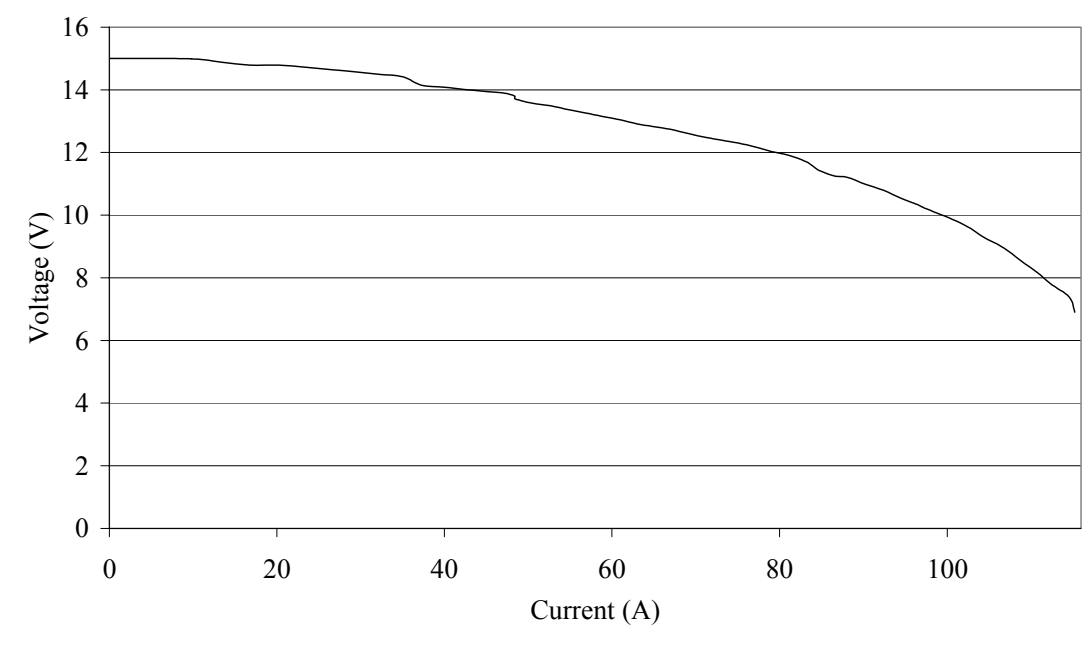

Figure 5. 1kW SSMCFC voltage/current characteristic curve after about 1500 working hours 
Working temperatures were measured by thermocouples into anodic and cathodic external subchambers: temperature range is $[645,650]^{\circ} \mathrm{C}$ during tests. Figure 5 shows Volt-Ampere characteristic after about 1500 working hours. Furthermore, a duration test on the proposed SSMCFC was led: no technical problems were occurred after about 5000 working hours. It was obtained that maximum power is about $996 \mathrm{~W}$. A single cell area is $706 \mathrm{~cm}^{2}$. Thus, maximum power density is $94.0 \mathrm{~mW} / \mathrm{cm}^{2}$; maximum current density is $136.9 \mathrm{~mA} / \mathrm{cm}^{2}$.

\section{SSMCFC Control and Monitoring system}

A control and monitoring system for SSMCFC was built. A graphic interface was also implemented (see Figs. 6 and 7). The system is constituted by the following subsystems:

- thermal subsystem (see Fig. 6): it is able to monitor stack internal temperatures by thermocouples and a data acquisition module. A PID regulation is also applied to the stack heating system.

- electrical subsystem: it monitors single cell voltage, stack current and voltage by Hall effect probes, inconel wires and data acquisition modules.

- flow rate subsystem: it controls and monitors the supplying gas flow rates by massflow probes, electrovalves and data acquisition and control modules (see Fig.7).

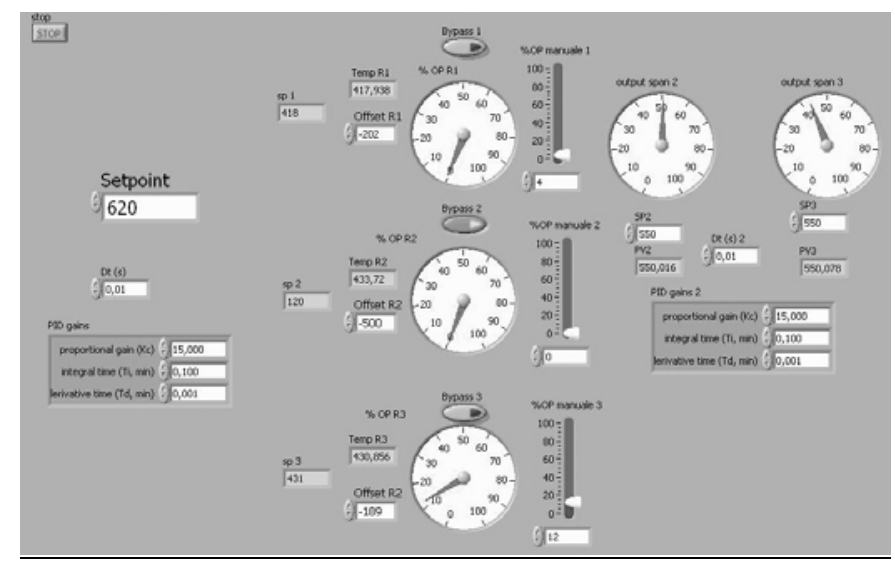

Figure 6. Control and monitoring system: temperature control mask

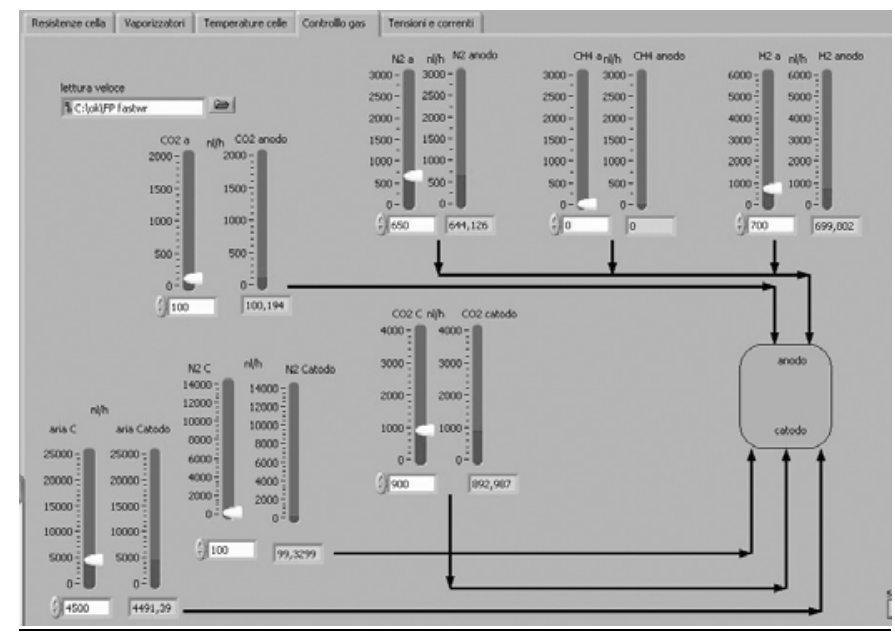

Figure 7. Control and monitoring system: gas flow rate monitoring mask 


\section{Evaluation of target price}

The optimized SSMCFC is the result of pluriannual activities carried out at the Fuel Cell Laboratory of University of Perugia headquartered in Terni (Italy). SSMCFC is patented by IPASS S.c.a.r.l., a partnership between CIRIAF (interuniversitary research center on physical agent pollution) and FN S.p.A. (an industrial partner). The proposed fuel cell technology has recently moved from laboratory scale stacks to commercial prototypes suitable for $\mu \mathrm{CHP}$ application. An economical evaluation was carried out to individuate the SSMCFC target price which is about $\$ 2000 / \mathrm{kW}$ (see Table 1). Target price is to be achieved in about 5 years if over 10000 target customers have to be covered.

TABLE I. SSMCFC target price.

\begin{tabular}{|c|c|c|c|c|c|c|}
\hline SSMCFC Components & $\begin{array}{c}\text { Plates } \\
\text { (sheets, } \\
\text { nettings, laser } \\
\text { cutting, } \\
\text { electrochemical } \\
\text { cleaning) }\end{array}$ & $\begin{array}{l}\text { Compression } \\
\text { system, } \\
\text { headboards, } \\
\text { vessel, } \\
\text { assembling }\end{array}$ & $\begin{array}{l}\text { Band } \\
\text { resistors }\end{array}$ & $\begin{array}{c}\text { Thermal } \\
\text { insulation } \\
\text { panels }\end{array}$ & $\begin{array}{l}\text { Electrodes, } \\
\text { matrices, } \\
\text { carbonates }\end{array}$ & TOTAL \\
\hline Target Price $(\$ / \mathrm{kW})$ & 650 & 600 & 150 & 250 & 350 & 2000 \\
\hline
\end{tabular}

\section{Ionic liquids for decreasing SSMCFC working temperature}

An investigation and preliminary tests were carried out on using ILs as electrolyte support in the optimized SSMCFC instead of a lithium aluminate porous material. In the traditional SSMCFC, carbonate liquefaction is needed in the carbonates-glycerine mixture starting at $500^{\circ} \mathrm{C}$. This phase may be avoided by using ILs, which are low melting point $\left(<100^{\circ} \mathrm{C}\right.$ ), thermally stable (up to $200^{\circ} \mathrm{C}$ ) salts which represent a new class of non-molecular, ionic solvents. They are able to solvate a broad spectrum of both organic and inorganic compounds, have low vapour pressure, are recyclable and easily handled $(5,6)$. ILs may help charge separation at temperatures lower than $150-200^{\circ} \mathrm{C}$; thus, they may be used as electrolyte or electrolyte support for SSMCFC in order to decrease its working temperature. A low temperature SSMCFC (LTMCFC) facility was built in order to test different electrolytic solutions made by ILs (solvent) and lithiumpotassium carbonates (solute). Tests were made by supplying the proposed facility with hydrogen. One of the very interesting aspects of ILs is the possibility to alter their physical and chemical properties by varying their structure, with respect to the choice of organic cations and anions, and side-chain attached to the organic cation; thus, ILs have been described as 'designer solvents' $(5,6)$. The ILs used in this study were 1-octyl-3methylimidazolium hexafluorophosphate (OMIM PF6, IL1) and 1-butyl-3methylimidazolium tetrafluoroborate (BMIM BF4, IL2). IL1 and IL2 were synthesized starting from 1-methylimidazole and the appropriate alkyl halide (alkyl = octyl for IL1 and butyl for IL2), and then by subjecting the obtained imidazolium chlorides to anion exchange with hexafluorophosphoric acid (IL1) or fluoroboric acid (IL2).

\section{The experimental facility for LTMCFC tests}

An experimental reactor was designed and built to test the new ILs-based matrices; it has a cylindrical shape. It is made by the following polytetrafluoroethylene (PTFE) components: 
1) LTMCFC compartment: it is the central compartment (see Figs. 8 and 9). The ILcarbonates electrolyte is installed here between the electrodes (the nickel-chrome porous anode and the nickel-oxide cathode). A metallic net is installed on each electrode external side for voltage-current measurements and as electrode support system. Anode, cathode and metallic nets are supported by a holed PTFE wall in the supplied gases side. The holed PTFE wall allows the gas tight and supplying.

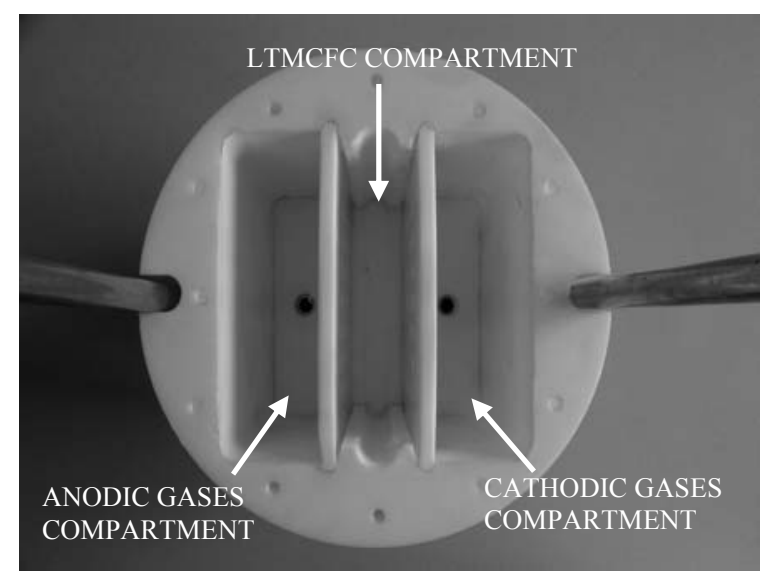

Figure 8. The experimental reactor (upside view)

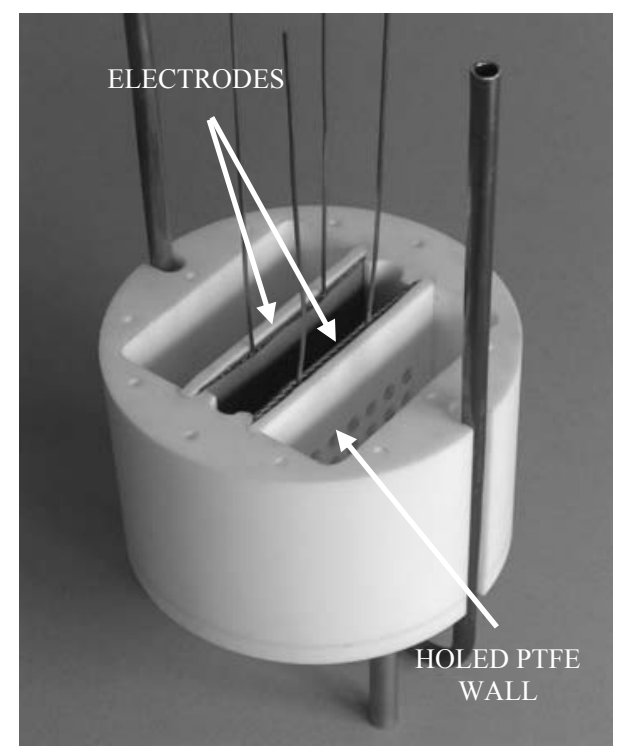

Figure 9. The experimental reactor (perspective view);

2) Anodic gases compartment (see Figure 8): it is connected to the anodic gases distribution system by copper pipes in the lateral side. Hydrogen and nitrogen are supplied to the anode by the holed PTFE wall;

3) Cathodic gases compartment (see Figure 8): it is connected to the cathodic gases distribution system by copper pipes in the lateral side. Air, carbonic dioxide and nitrogen are supplied to the cathode by the holed PTFE wall.

4) A plug which closes the reactor. The plug is characterized by (see Figure 10):

- anodic and cathodic outlets over the electrode compartments; 
- a central hole for the installation of a thermocouple for electrolyte temperature measurements;

- four holes (two for each electrode net) for voltage and current measurements by copper leads;

- a plugged hole for electrolyte solution restoring over the electrolyte compartment;

- two groovings in the plug bottom side for electrodes and metallic nets casing.

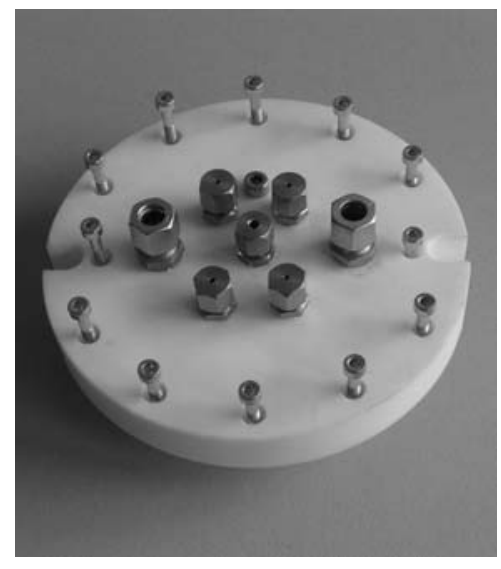

Figure 10. The reactor plug

A pressurization system allows keeping the gases compartments at a pressure 50mbar higher than the LTMCFC one; this adjustment increases the electrolyte solution tight. The experimental facility is made by the reactor, a gas supplying system and a heating system. The heating system is made by a thermostatic bath constituted by silicon oil in a steel box. An electromagnetic agitator and heater allows the bath uniform heating. Moreover, the facility was thermally insulated during the tests in order to minimize the thermal dispersions. The facility is shown in Figure 11.

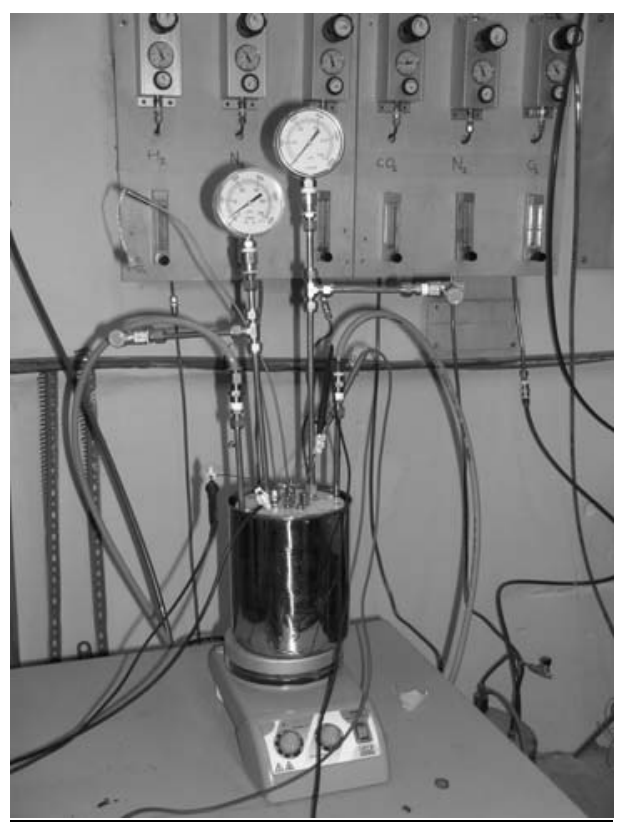

Figure 11. The experimental facility 


\section{The LTMCFC experimental tests}

Experimental tests were made by the LTMCFC facility with different electrolyte solutions constituted by ILs and carbonates. Two kinds of ILs were tested (identified by IL1 and IL2 codes). Their characteristics in terms of kinematic viscosity (measured by Ubbelohde viscosimeters soaked into thermostatic baths) and electrical conductivity (measured by a conductivimeter) are shown in Table 2. The tested electrolyte solutions were made by the ILs (solvent) and carbonates (solute) $5 \%$ or $9.7 \%$ by weight. It was verified that carbonates mixing does not modify the electrical conductivity of the ILs.

TABLE 2. The tested ILs characteristics.

\begin{tabular}{lcc}
\hline Ionic liquid & $\begin{array}{c}\text { Kinematic viscosity at } \mathbf{2 5}^{\circ} \mathbf{C} \\
\left(\mathbf{m}^{\mathbf{2}} / \mathbf{s}\right)\end{array}$ & $\begin{array}{c}\text { Electrical conductivity at } \mathbf{2 5}^{\circ} \mathbf{C} \\
(\mathbf{S} / \mathbf{m})\end{array}$ \\
\hline IL1 & $3.46^{*} 10^{-4}$ & 0,02 \\
IL2 & $3.87 * 10^{-5}$ & 0,12
\end{tabular}

Tests were made for three LTMCFC temperatures: 50, 100 and $150{ }^{\circ} \mathrm{C}$. Open-circuit voltages were measured and electrical loads were applied to measure the electrical current on a closed circuit. Table 2 reports open-circuit voltages, $1.5 \mathrm{ohm}$ load voltages and $1.5 \mathrm{ohm}$ load currents. Results shows that only IL1 allows the LTMCFC working. IL2 application does not produce voltage and obviously current. Gascromatographic analyses were made on inlet and outlet gases relatively to IL1 tests; results verified that the reaction occurs correctly both for cathodic and anodic compartment.

TABLE 3. Experimental tests results (IL1-based electrolyte).

\begin{tabular}{lcccc}
\hline Electrolyte & $\begin{array}{c}\text { Temperature } \\
\left({ }^{\circ} \mathbf{C}\right)\end{array}$ & $\begin{array}{c}\text { Open-circuit } \\
\text { voltage } \\
(\mathbf{V})\end{array}$ & $\begin{array}{c}\text { Voltage } \\
\text { produced when a } \\
\mathbf{1 . 5} \text { ohm load is } \\
\text { applied } \\
(\mathbf{V})\end{array}$ & $\begin{array}{c}\text { Current produced } \\
\text { when a 1.5 ohm load is } \\
\text { applied } \\
\text { (mA) }\end{array}$ \\
\hline IL1+carbonates solution & 50 & 0.062 & 0.010 & 0.030 \\
(carbonate 5\% by weight) & 100 & 0.037 & 0.010 & 0.042 \\
& 150 & 0.032 & 0.020 & 0.060 \\
IL1+carbonates solution & 50 & 0.068 & 0.010 & 0.021 \\
(carbonate 9.7\% by weight) & 100 & 0.038 & 0.013 & 0.041 \\
\hline
\end{tabular}

In particular, IL1-carbonates solution works as good electrolyte when the carbonate percentage is about $10 \%$ by weight at $150^{\circ} \mathrm{C}$. Otherwise, very low current is measured (also for different electrical loads) for lower temperatures or lower carbonates percentage. Thus, the reported preliminary tests allows defining the proposed matrix as possible solution for decreasing MCFC working temperature.

\section{Conclusions}

A cylindrical SSMCFC was proposed and tested. The final SSMCFC configuration was obtained by applying optimizing adjustments on the preliminary proposal (1). Voltage/current performances, maximum power density and current density were evaluated for a $1 \mathrm{~kW}$ optimized SSMCFC. The final configuration was built and tested at the Fuel Cell Laboratory of University of Perugia headquartered in Terni (Italy). Experimental tests results suggested that the proposed SSMCFC stacks are suitable for $\mu \mathrm{CHP}$ fuel cell applications because of high performances compared to low realisation 
costs and viability for industrialisation processes. SSMCFC main peculiarity is the innovative stack architecture which is characterized by a cylindrical compact geometry and an original gases distribution systems. Main SSMCFC technology benefits are:

- $\quad$ high electrical efficiency (up to $40 \%$ );

- thermal self-sustain conditions kept down to $\mathrm{kW}$-size stack because of very low heat losses due to cylindrical geometry and an innovative gas recirculation;

- multy fuel supply because of original high surface/volume ratio catalyzers;

- low cost components;

- not pressurized devices;

- long-life (a duration test was carried out and no technical problems occurred after 5000 working hours)

- $\quad$ sealing is enhanced because of the absence of edges;

- counter-flow gas feeding and gas exhausting;

- compact design;

- modularity thank to internal manifolds;

- low external temperature.

An economical evaluation was carried out to individuate the SSMCFC target price: the target price is $\$ 2000 / \mathrm{kW}$ to be achieved in about 5 years if over 10000 target customers have to be covered. The main problem which may characterize SSMCFCs is due to the high working temperatures (about $650^{\circ} \mathrm{C}$ ); high temperatures and the typical used electrolyte may accelerate the cell components breakdown and corrosion. Preliminary experimental tests were carried out to verify the suitability of a proposed ionic liquidbased matrix for SSMCFCs: the matrix is constituted by a solution of a ionic liquid (IL) and lithium-potassium carbonates. An experimental facility was built constituted by a reactor, a heating system and a gas distribution system. Two kinds of ILs were tested as support for SSMCFC matrix. Tests were carried out for temperatures up to $150^{\circ} \mathrm{C}$. Results showed that IL1 ionic liquid may be a good solution for decreasing SSMCFC temperature and increasing SSMCFC life. The optimized solution may help to build low temperature SSMCFC (LTMCFC) limiting components corrosion and breakdown problems. Future developments regards an investigation on the employment and the installation of an electrolyte constituted only by ILs (no carbonates have to be used) on the proposed SSMCFC.

\section{References}

1. F.Cotana, F.Rossi and A.Nicolini, A New Geometry High Performance Small Power MCFC, in Journal of Fuel Cell Science and Technology, Vol.1, Issue 1, pp.25-29, ASME (2004).

2. F.Rossi, U.Di Matteo and A.Nicolini, New solutions and materials for Molten Carbonate Fuel Cells, CD Proceedings of Fuel Cell 2004 Seminar, San Antonio, USA, 1-5 November 2004.

3. F.Rossi, U. Di Matteo, A.Nicolini and M. Filipponi, Performances of a New Cylindrical Molten Carbonate Single Cell, CD Proceedings of Fuel Cell 2005 Seminar, Palm Springs, USA, 14-18 November 2005.

4. IPASS, Dispositivo Termoelettrochimico a Carbonati Fusi per la Generazione Contemporanea di Elettricità e Calore a Geometria Cilindrica, Ministero dell'Industria, del Commercio e dell'Artigianato, Patent N. PG2003A0019, Italy, (2003). 
5. L. Brinchi, R. Germani and G. Savelli, Ionic liquids as reaction media for esterification of carboxylate sodium salts with alkyl halides, in Tetrahedron Letters 44, 2027-2029 (2003).

6. L. Brinchi, R. Germani and G. Savelli, Efficient esterification of carboxylic acids with alkyl halides catalyzed by fluoride ions in ionic liquids, in Tetrahedron Letters 44, 6583-6585 (2003). 